\title{
Strategic Information Systems Planning (SISP) Practices In Health Care Sectors Of Bangladesh
}

\author{
Md. Rakibul Hoque \\ University of Dhaka, Bangladesh \\ Md. Ekram Hossin \\ Babylon Group, Bangladesh \\ Wahiduzzaman Khan \\ Asian University of Bangladesh
}

doi: 10.19044/esj.2016.v12n6p307 URL:http://dx.doi.org/10.19044/esj.2016.v12n6p307

\begin{abstract}
Strategic Information Systems Planning (SISP) has been a topic of considerable importance and interest to Information Systems (IS) professionals since the 1970's and consistently ranked as a top issue for IS executives in both developed and developing countries. Studies have shown that SISP can assist manager in defining the information systems, develop IS strategy, and allocate resources for IS strategy. However, the use of SISP in healthcare sectors in developing countries like Bangladesh is underdeveloped and under-researched. This study examined the benefits of SISP in healthcare organization in developing countries in general and Bangladesh in particular. This study also focused on the current practice and key implementation challenges of Strategic Information Systems Planning (SISP) in healthcare sectors in developing and transitional economies. Finally, some recommendations are proposed to overcome the challenges using a 'hybrid' approach.
\end{abstract}

Keywords: SISP, Bangladesh, Strategy

\section{Introduction}

Over the past two decades, Information Systems (IS) has viewed significant growth. Worthen (2007) showed that $87 \%$ of business leaders identified information systems as a critical resource in their business strategy's success. Evidence also shows ninety four percent surveyed managers agreed that IT-based systems are very important in the delivery of their organizational strategy (ITGI 2011). Galliers (2007) indicated that firms with defined IS strategies perform better than those without defined IS strategies. 
Recently, researchers have shown an increased interest in development of Information system. It is argued that innovative ways of providing efficient healthcare services such as e-Health is accompanied by IS Strategy (Alrajeh et al, 2012).A recent research has confirmed the importance of IS strategy in healthcare sectors in Bangladesh (Hoque et al, 2014). The Government of Bangladesh has placed a high priority on IS strategy in healthcare and e-Health strategy, which is reflected in the ICT Policy 2009. The ultimate goal of IS strategy in healthcare or e-Health strategy is to improve health condition of citizen by providing good quality, accessible knowledge, affordable service and care with the use of ICT tools (Digital Bangladesh, 2011). There are increasing national and international effort to develop long-term country-specific vision, goal, policy, and strategy for healthcare in general and e-Health in particular in Bangladesh (Health Bulletin, 2013).

Many private and public hospitals in Bangladesh are now at a crossroads in terms of information systems (IS) strategy. Braa et al. (2007) have identified a number of strategies for the development of IS support for the healthcare organization in low and medium income countries. They also argued that IS strategy is the most important strategy for healthcare in developing countries. Increasing use of information systems strategies can bring the political, financial and organizational benefit to healthcare in Bangladesh. Senior management control over organization, competitive advantages, cost saving, higher IS project priority, better fit between service provider and receiver objectives, detailed plan of actions and reducing risk might be ensured by IS strategy (Heeks, 2014).

However, the use of IS strategy in healthcare sectors in developing countries like Bangladesh is under-developed and under-researched. The objective of this study is to examine the benefits of IS strategy in healthcare organization in developing countries in general and Bangladesh in particular. This study also focused on the current practice and key implementation challenges of Strategic Information Systems Planning (SISP) in healthcare sectors in developing and transitional economies. Finally, some recommendations are proposed to overcome the challenges using a 'hybrid' approach.

\section{Literature Review}

Information System (IS) strategy originate from the literature on strategic management which is ambiguous due to the lack of established structure and theoretical foundation (Daniel et al., 2010). Until recently, researcher are not in consensus in terms of finding a uniform definition of IS strategy (Gottschalk, 1999;Smits et al., 1997; Chan et al., 1997). The initial work on IS strategy led by Earl (1989) who defined IS strategy "as 
comprised of an information strategy, an information technology strategy, an information management strategy, and a change management strategy". This definition illustrates that these components collectively represent the IS strategy needed in managing information systems in an organization. Chen et al. (2010) define IS strategy as "the organizational perspective on the investment in, deployment, use, and management of information systems'. It highlights the resources, position, plan and perspective of IS strategy.

A survey of 260 Fortune one thousand manufacturing firms shows that the average company expends $\$ 9.6$ million per year on IT services, which constitute $15 \%$ of the total cost for R\&D and $0.3 \%$ of total sales (Kleis et al., 2012). The effectiveness of these investments depends on strategic planning for IT/IS (Krell\&Matook, 2009). However, Information System strategy never will be a plan for everything. Appropriate methodologies such as SISP and timely implementation are needed for success.

SISP is defined as "the process of deciding the objectives for organizational computing and identifying potential computer applications which the organization should implement” (Lederer and Sethi, 1988). Reich and Benbasat (2000) defined SISP "as the processes of identifying a portfolio of computer-based applications that will support an organization's business plan, thus enabling the organization to align its information systems with its business needs and achieve its business goals".

SISP has been a topic of considerable importance and interest to IS professionals since the 1970's and consistently ranked as a top issue for IS executives in both developed and developing countries (Luftman\&Derksen 2012; Watson et al. 1997). Studies have shown that SISP can assist manager in defining the information systems, develop IS strategy, and allocate resources for IS strategy (Basu et al, 2002).

\section{Information Systems Strategy in Healthcare Sectors}

Information Systems (IS) strategy is already in place in healthcare sectors in developing and transitional economies like Bangladesh, and spreading due to the changes, growth in competition and diffusion of technology (Heeks, 2014). When organization like healthcare realized the benefits of IS strategy, they should move onto how to prepare the IS strategy plan, when and why they implement for healthcare sectors in developing countries. This section described one of the methodologies for IS strategy, Strategic Information Systems Planning (SISP), in healthcare sectors in the context of developing countries like Bangladesh.

To keep pace with global trend, Bangladesh government hired international expert, with technical assistance from DFID to draft the National e-Health Strategy and National IS Strategy in healthcare. WHOITU has developed a standard toolkit, with guidance on how to proceed step- 
by-step to build up a well-represented national e-Health strategy or IS strategy in healthcare (Health Bulletin, 2013).Many hospitals in Bangladesh apply SISP, a multi-step process, which includes identifying mission, vision, goals and strategies (Ward et al, 2014). At the healthcare sectors in Bangladesh, IS include different systems and manage data related registration, clinical guidelines, health record, nursing, pharmacy, financial and administrative. SISP can improve the efficiency of the healthcare systems in Bangladesh, and thus perhaps gain a competitive advantage (Doherty et al. 1999; Wiggins, 1995).

SISP is a series of steps that are implemented systematically over a period of a few days, weeks or months depending on the size and type of the organization (Heeks, 2014c). The steps of implementing SISP in healthcare of Bangladesh are summarized in Figure 1. The SISP process consists of strategic awareness, situation analysis, strategy conception, strategy formulation, and strategy implementation (Newkirk et al., 2003). Strategic awareness is the planning process in an organized way with adequate top management support. It determines key planning issues, defines planning objectives, organizing the planning team, obtaining top management commitment and analyzing the current environment. Situation analysis is the analyzing of the external and internal environments in which the planned information systems will be expected to contribute (Al-Aboud, 2011). It analyses current business systems, current organizational systems, current information systems, the current external business environment, and conceiving strategy alternatives. Strategy conception is the imaging of various possible information systems that might be implemented. It identifies major IT objectives, high level IT strategies, opportunities for improvement, selecting strategy and evaluating opportunities for improvement (Newkirk et al., 2003).

Strategy formulation is the selecting and prioritizing of the specific information systems that will be implemented. It identifies new business processes, specific new projects, new IT architectures, priorities for new projects and planning strategy implementation. Strategy implementation is the planning of the activities necessary to ensure that the new information systems are actually placed into production and used (King, 2009). It defines change management approach, action plan, and evaluating action plan. 
Figure 1: Strategic Information Systems Planning (SISP)

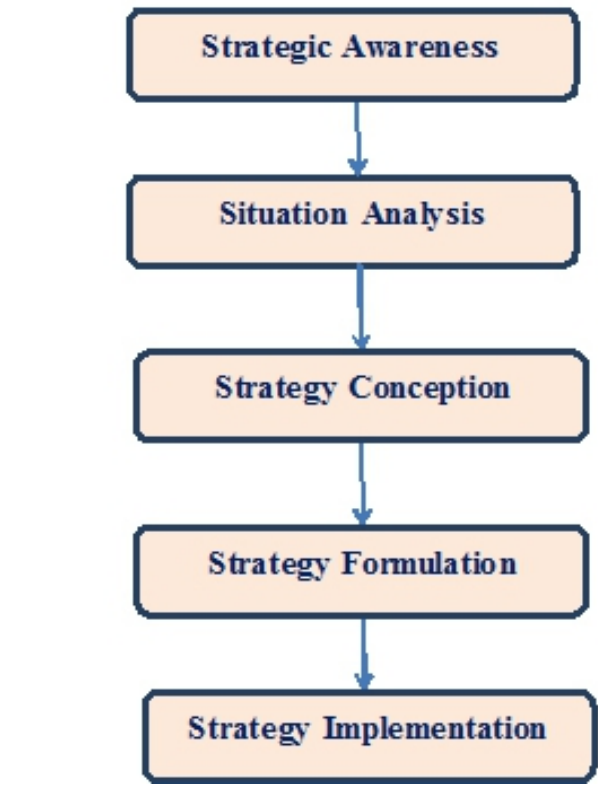

Source: Newkirk et al. (2003)

Newkirk et al. (2008) conclude that too little or too much SISP may not be effective; they argued that the suitable amount of implementation planning is needed to have successful SISP. Theyalso suggest that more planning is required in the early stages of implementation. The right time and right activities are the main factors of successful implementing IS strategy. Cheong et al (2011) provide high-level stages of the SISP (Table 1) which guides the healthcare organization in Bangladesh to establish when and what activities will be prepared for IS strategy.

Table 1 Maturity model

\begin{tabular}{|c|c|}
\hline Stages & Activities \\
\hline SISP Formulation & $\begin{array}{c}\text { Analyzing environments (external and internal), positioning IS/IT in } \\
\text { business, identifying issues and opportunities, describing current } \\
\text { systems, trends and issues. }\end{array}$ \\
\hline SISP Formation & $\begin{array}{c}\text { The generation of SISP, awareness, motivation, and alertness of SISP, } \\
\text { implementation of strategies described in the SISP. }\end{array}$ \\
\hline Evaluation & Perception and knowledge of how SISP is progressing. \\
\hline
\end{tabular}

Source: Cheong et al. (2011)

\section{Challenges of SISP Implementation}

Although SISP is a major concern in healthcare sectors in Bangladesh, most organizations in developing countries find it difficult to implement it. Lack of experience with SISP, difficulty in using methodology, absence of a comprehensive, may also be the main reasons for this difficulty(Pant and Hsu, 1995). SISP is a prescription based on rational 
models that are more theoretical than empirical and questionable particularly in public healthcare (Heeks, 2011). It may face some constraints to implement and causes negative impact such as lack of strategy, underused strategy, damaging strategy and alternative approach within healthcare sectors in developing countries (Heeks, 2011).

Studies show that there are different barriers and difficulties arise in SISP implementation in healthcare organizations in developing and transitional economies like Bangladesh (Lederer\&Sethi, 1988; Wilson, 1989; Kearns, 2007). Lederer and Sethi (1988) highlighted the top nine problems of SISP implementation such as

(a) Difficult to secure top management commitment;

(b) Post-analysis is necessary after the study;

(c) There is no training plan for IT development;

(d) Success depends on the IT leader;

(e) Difficult tofind a team leader who meets the criteria;

(f) Lack of sufficient computer support;

(g) Ignores plan implementation issues;

(h) There is no analysis of IT department strengths and weaknesses;

(i) There is no analysis of technological environment.

Lederer and Sethi(1991) classified the detailed list of problems in implementing SISP methodologies as output, resource, or planning process. According to their survey, the most critical problem identified by IS managers is the failure to secure top management commitment. The second most important problem is the substantial further analysis after completing IS plan. Both these problems are related to the output of the planning process. Six of the next top nine problems are related to the resources required to carry out the strategic information systems planning (lacking computer support, depends on the team leader, difficulty in finding the team leader meeting the criteria, planning exercise taking long time, etc.). Among the top nine problems of this methodology, three are common: difficulty in gaining top management commitment for implementing the outputs, the substantial further analysis and difficulty in finding a competent team leader (Hartono et al., 2003).

Another study by Teo and Ang (2001) have identified 14 problems of SISP implementation in developing countries. However, they highlighted 7 as the most important, i.e. failing to get management support, not having free communication and commitment, unable to obtain sufficiently qualified personnel, distributing the planning responsibility to an individual without sufficient knowledge and experience, not investing sufficient front-end time, not having steering committee and not having a clear-cut corporate plan to guide the information systems planning effort. Teo and Ang (2001) also revealed that failing to secure top management support is the most serious 
SISP problem. Samaha and Dahawy (2010) found that lack of expertise within the organization is the main problem in SISP implementation. Unnecessary expenses, and fail to recognize the benefits are the others problems in SISP implementation.

The various difficulties of SISP include both managerial and technological factors; furthermore, research has indicated that SISP aims and objectives are different from one organization to another (Teubner, 2007). In the same way, Pyburn (1983) recommended that organizational context is one way of determining the best method to plan for information systems. Nevertheless, Grover and Segars (2005) established a relationship between the planning processes used in SISP and the effectiveness of the plan, and proposed that the processes oughtto be evaluated further in relation to the organizational context. So far, however, only a few studies have pointed out that the success or failure of SISP is the combination of planning processes and the organizational context (Grover, 2007).

Healthcare organization is always complex social systems comprising stakeholders with different backgrounds, experiences and values. Therefore, the successful implementation of SISP in healthcare organization does not depend only the infrastructure but also culture and environment. It is important to understand the impact of the social and human factors which influence implementation of SISPin organization in developing and transitional economies (Lee and Pai, 2003).

Difficulties with implementing SISP in healthcare in developing countries have, however, been many. The key challenges of implementing SISP in developing countries like Bangladesh relate are related to costs, lack of ICT skills, scarcity of human recourses, donor policies (Kimaro\&Nhampossa, 2005; Jacucci et al., 2006). The most prominent research on IS strategy implementation in healthcare in developing countries has shown that the challenges are not only related to the technology itself (Sahay et al., 2006). Power dynamics, politics, and other social aspects are often what makes the difference between functioning and non-functioning SISP in healthcare sectors (Nyella\&Mndeme, 2010; Chilundo\&Aanestad, 2005).

Previous studies have also shown that healthcare professionals and administration was a great barrier and they have lack of motivation and encouragement to implement SISP in healthcare sectors in Bangladesh. Moreover, the senior manager, end user (i.e. physicians, nurses, patients) and administrative are unfamiliar with computers, IT, IS and did not have knowledge about how to use them, and the benefits they might bring. Cultural environment of healthcare, especially public healthcare sectors, in Bangladesh where the familiar system and strategy has been prevailing for decades and nobody wants to take the risk of implementing new ideas in an 
old setup. This is one of the bigproblems to implement SISP in healthcare sectors in Bangladesh (Khan et. al, 2012)

Developing countries like Bangladesh, whose per capita income 1314 USD, faces economic challenges when implementing SISP. It is not only includes budget for infrastructure but also budget for human and IT resources. It is already probed that financial problem was a major challenge regarding the implementation of SISP in healthcare in Bangladesh (Hoque et al., 2014). According to WHO, total health expenditure in Bangladesh is 3.5\% of GDP in 2012 (WHO, 2012). Expected challenges such as need for training, lack of ICT personnel, lack of ICT resources \& infrastructure, all have their roots in the financial constraints of the health sector in Bangladesh .Although Bangladesh has large population (156 million), it has been identified as one of 57 countries in the world with a critical shortage of health workforce (doctors, nurses and midwives number below 2.28 per 10,000 populations) and IT workforce in healthcare (WHO, 2012).

\section{Analysis of Addressing the Key Challenges of SISP:}

In the context of healthcare organization in Bangladesh, identified key challenges are budget, healthcare environment and culture, lack of resources, lack of motivation of top level management and end user involvement. It is also known that SISP approach is very complex, more technology focused and time consuming in the context of healthcare in developing countries (Heeks et al., 2000). Researchers in healthcare sectors in developing countries also found that SISP increase the time gap between the acquisition of the hardware and development of the custom software so that by the time software is ready for use, the hardware becomes obsolete (Hoque et al., 2014). Wall et al. (2013) explored that over techno-centric approach and strategy, which focuses mainly on technological aspect, is the main reason for different e-Health and m-Health project failure in lowand middle-income countries.

However, Heeks(2002) argued that 'failure to learn' is one of the main issues in the organizations in developing countries. It is obvious that there is no one single, agreed best approach to IS management (Heeks, 2014). Although there are problems with SISP, but there are also benefits. It is also true that SISP also applicable in developing countries like Bangladesh. Heeks(2014) suggest that using 'hybrid' approach, as illustrated in Figure 2, is the best solution for healthcare organization in developing countries like Bangladesh to implement IS strategy in effective and efficient way. Hybrid approach is the way of crossbreed of centralized and decentralized, of top-down and bottom-up approach. Moreover, hybrid approach can avoid repetition, quicker and more effective information flow within an organization, control to share key resources, and overcome blocks 
to systems development and IT usage (Heeks, 2014). Therefore, Hybrid approach to IS strategy will be more appropriate for most of the healthcare organization in most circumstances (Heeks, 2014). It appears to be more effective than the highly structured and rational approaches (Osman, 2012).

Figure 2 Hybrid Approach

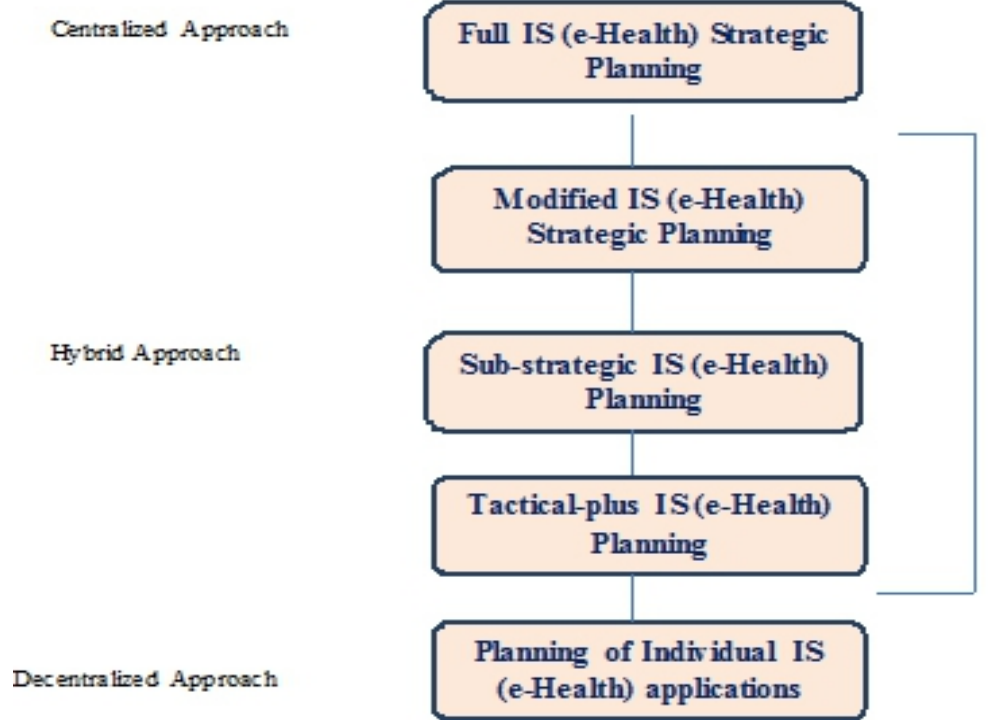

Source: Adapted from Heeks (2014)

Wall et al. (2013) found that implemented as top-down initiatives, the exclusion of end-users from development processes, is the causes of failure of e-Health and m-Health project in developing countries like Bangladesh. In modified IS strategic planning, strong strategic component of hybrid approach, end users and local units will involve in the formulation and development process of strategy which will help healthcare organization in Bangladesh to implement IS strategy in more better way. Moreover, end user involvement (i.e. doctor, patients, nurses) in the strategy formulation and development process can overcome the cultural challenges, which is one of the key challenges in IS strategy implementation in healthcare organization in Bangladesh. Modified IS strategic planning can also overcome the financial challenges of IS strategy implementation in developing countries like Bangladesh. This modified approach also incorporates the more flexible notion of strategy as guidelines rather than blueprint, "allowing for revisions based on experiences from the ongoing process of change" (Nilsson \&Ranerup, 2002).

Sub-strategic IS may be more feasible to plan at the "sub-strategic" level. It will help executives in healthcare organization in developing countries like Bangladesh to prepare plan based on an external and internal survey of information-related needs and problems (Heeks 2014). It would 
priorities and then addresses the selecting steps and techniques which can be implemented. It also focuses on common tools (i.e. SWOT, value chain analysis, benchmarking) rather than any particularly detailed approaches. Tactical-plus IS planning, another strong strategic component of hybrid approach, might be useful to overcome the environmental, power dynamics, politics, and other social aspects challenges for implementing SISP in healthcare sectors in Bangladesh. It is also an attempt to broaden the scope of planning and place such systems in healthcare organizational context (Heeks, 2014).

In real world organization hybrid managers are needed to apply hybrid approach. There is increasing belief that the problems facing by organization in their IT departments are neither fiscal nor technical, but managerial and organizational. Meiklejohn (1989) was one of the first writers who identify the need for hybrid managers. Hybrid manager combines business understanding, organizational knowledge \& skills and technical competence to integrate IT with business (Meiklejohn, 1989). Such person is important in enabling healthcare organizations in developing countries to implement information systems and IS Strategy effectively and efficiently in today's competitive environment (Earls and Skyrme, 1992). Hybrid roles were first suggested by Keen (1986), but hybrid managers were seen by Earl (1989). Thus Earl's definition is the most precise one available to date. Earl (1989) defined hybrid manager as "people with strong technical skills and adequate business knowledge, or vice versa. Hybrids are people with technical skills able to work in user areas doing a line or functional job, but adept at developing and implementing IT application ideas"

O'Connor and Smallman (1995) mentioned that 'hybrid' combine different competencies together. They suggest that the "more 'hybridized' you can become, the better for you and your organization". Therefore, healthcare organization in Bangladesh needs more hybrid managers who can apply hybrid approach in their organization to address the challenges of SISP implementation. Hybrid framework in the strategy planning process balance the needs of external and internal stakeholders in setting priorities; help to plan which data items are specific and which are generic; divide the responsibilities for information systems and IS strategy development and implementation (Heeks, 2014). Finally, hybridization is the way that the strategy process is implemented properly.

\section{Conclusion}

This paper described the importance of IS strategy and identified the problems of IS strategy implementation in healthcare organization in developing countries like Bangladesh. SISP is already in place in healthcare sectors in Bangladesh, and spreading due to the changes, growth in 
competition and diffusion of technology. One of the more significant findings to emerge from this study is that the strong relationship between the success or failure of SISP and the success or failure of information systems in developing and transitional countries. In developing countries there are some inherent challenges in developing an IS strategy for a healthcare system. In that respect, and in order to achieve alignment of strategy between entities, the best solution for healthcare organization in developing countries is to introduce hybrid approach as a way of describing where SISP fits in the organizational process and modified SISP accordingly.

\section{References:}

Al-Aboud, F. N. (2011). Strategic information systems planning: A brief review. International Journal of Computer Science and Network Security, 11(5), 179-183.

Alrajeh, N., Elmir, B., \&Bounabat, B. (2012).Healthcare Strategic Alignment through Interoperability Reinforcement.In CONTECSIInternational Conference on Information Systems and Technology Management (Vol. 9, No. 1, pp. 1365-1375).

Basu V., Hartono E., Lederer A. L, Sethi V (2002). The impact of organisational commitment, senior management involvement, and team involvement on strategic information systems planning, Information \& Management, Vol.39 No 6 pp: 513-524.

Braa, J., Hanseth, O., Heywood, A., Mohammed, W., \& Shaw, V. (2007).Developing health information systems in developing countries: the flexible standards strategy.MIS Quarterly, 381-402.

Chan, Y.E., Huff, S.L., Barclay, D.W., Copeland, D.G., (1997). Business strategic orientation, information systems strategic orientation, and strategic alignment, Information Systems Research 8 (2), 125-150.

Chen, D.Q., Mocker, M., Preston, D.S., Teubner, A., (2010). Information systems strategy: reconceptualization, measurement, and implications. MIS Quarterly, 34 (2), 233-259.

Cheong, F., Corbitt, B., \& Pita, Z., (2011). A maturity model of strategic information systems planning (SISP): A comprehensive conceptualization. International Journal of Enterprise Information Systems (IJEIS), 7(3), 1-29.

Chilundo, B. \&Aanestad, M. (2005) Negotiating Multiple Rationalities in the Process of Integrating the Information Systems of Disease Specific Health Programmes.TheElectronic Journal on Information Systems in Developing Countries, 20, 2, 1-28.

Chrisanthi, A. (2008). Information Systems in Developing Countries: a Critical Research Review, Journal of Information Technology, Vol.23, pp. 133-146. 
Daniel Q. C, Martin M, David S. P, (2010). Information systems strategy: Reconceptualization, measurement, and implications, MIS Quarterly, Vol. 34 No. 2, pp. 233-259.

Digital Bangladesh (2011). Strategic Priorities of Digital Bangladesh Report, January 2011, Access to Information (A2I) Programme, Prime Minister's Office, Bangladesh Government.

Doherty, N., Marples, C., \&Suhaimi, A. (1999). The relative success of alternative approaches to strategic information systems planning: an empirical analysis. The Journal of Strategic Information Systems, 8 (3), 263283.

Earl, M.J., (1989). Management Strategies for Information Technology.Prentice Hall, London.

Earl.M.J. (1989).Management Strategies for information Technology.Prentice-Hall, Hemel Hempstead.

Earls, M. J., \&Skyrme, D. J. (1992). Hybrid managers-what do we know about them?.Information Systems Journal, 2(3), 169-187.

Earl, M. J (2003). Approaches in Information Systems Planning in R. D. Galliers\& D. E. Leidner (Eds.), Strategic information management: Challenges and strategies in managing information systems. (3rd. ed., pp. 181-215). Oxford: Butterworth-Heinemann, 2003.

Galliers, R.D., (2007). On confronting some of the common myths of Information Systems strategy discourse. In: The Oxford Handbook of Information and Communication Technology. Oxford University, Oxford, pp. 225-243.

Gottschalk, P. (1999). Implementation of formal plans: the case of information technology strategy. Long Range Planning, 32 (3), 362-372.

Grover K. S. (2007). How the Internal Environment Impacts Information Systems Project Success: An Investigation of Exploitative and Explorative Firms, Journal of Computer Information Systems, Vol. 48 No.1, pp.63-75.

Grover, V., \&Segars, A. H. (2005). An empirical evaluation of stages of strategic information systems planning: patterns of process design and effectiveness. Information \& Management, 42(5), 761-779.

Hartono, E., Lederer, A. L., Sethi, V., \& Zhuang, Y. (2003).Key predictors of the implementation of strategic information systems plans.ACM SIGMIS Database, 34(3), 41-53.

Health Bulletin (2013).Ministry of Health and Family Welfare, Government of the People's Republic of Bangladesh

Heeks, R. (2002). Information systems and developing countries: Failure, success, and local improvisations. The information society, 18(2), 101-112. Heeks, R. (2011). Implementing and managing eGovernment: an international text. Sage. 
Heeks, R. (2014). Information Systems Strategic Planning, Issues in the Management of Information Systems Course Unit Handout, IDPM, University of Manchester, Manchester.

Heeks, R., Mundy, D., \& Salazar, A. (2000).Understanding success and failure of health care information systems.Healthcare information systems: challenges of the new millennium, 96-128.

Hoque, M. R, Mazmum, F. A \&Bao, Y. (2014). E-health in Bangladesh: Current Status, Challenges, and Future Direction, International Technology Management Review, June 2014, Vol. 4, No. 2.

ITGI (2011) Global Status Report on the Governance of Enterprise IT 2011, IT Governance Institute, Rolling Meadows, IL http://www.isaca.org/Knowledge Center/Research/Documents/ GlobalStatus-Report-GEIT-10Jan2011-Research.pdf

Jacucci, E., Shaw, V. \&Braa, J. (2006) Standardization of Health Information Systems in South Africa: The Challenge of Local Sustainability. Information Technology forDevelopment, 12, 3, 225-239.

Kearns, G. S. (2007). How the Internal Environment Impacts Information Systems Project Success: An Investigation of Exploitative and Explorative Firms”, Journal of Computer Information Systems, Vol. 48 No.1, p63-75.

Keen, P. G. W. (1986).Organizing for Telecommunications: Ch. 8. In: Competing in Time: Using Telecommunicationsfor Competitive Advantage. Ballinger. Cambridge, Massachusetts.

Khan, S. Z., Shahid, Z., Hedstrom, K., \&Andersson, A. (2012). Hopes and Fears in Implementation of Electronic Health Records in Bangladesh. The Electronic Journal of Information Systems in Developing Countries, 54.

Kimaro, H.C. \&Nhampossa, J.L. (2005) Analyzing the Problem of Unsustainable Health Information Systems in Less-Developed Economies: Case Studies from Tanzania and Mozambique. Information Technology for Development, 11, 3, 273-298.

King, W. R. (2009). Planning for Information Systems, Advances in Management Information Systems Service New York: M.E, Sharpe, Inc Kleis, L., Chwelos, P., Ramirez, R.V., \& Cockburn, I., (2012). Information technology and intangible output: The impact of IT investment on innovation productivity. Information Systems Research, 23(1), 42-59.

Krell, K., \&Matook, S. (2009). Competitive advantage from mandatory investments: An empirical study of Australian firms. The Journal of Strategic Information Systems, 18(1), 31-45.

Lederer, A. L. \&Sethi, V., (1988).The Implementation of Strategic Information Systems Planning Methodologies.MIS Quarterly, pp. 445-461.

Lederer, A. L., \&Sethi, V., (1991). Critical Dimensions of Strategic Information Systems Planning. Decision Sciences, 22(1), 104-104. 
Lee, G. G., \&Pai, J. C. (2003). Effects of organizational context and intergroup behaviour on the success of strategic information systems planning: an empirical study. Behaviour\& Information Technology, 22(4), 263-280.

Luftman, J., \&Derksen, B. (2012). Key Issues for IT Executives 2012: Doing More with Less. MIS Quarterly Executive, 11 (4).

Meiklejohn, I. (1989). A new hybrid breed for IT”, Management Today, pp. 143-6.

Newerik, H. E., Lederer, A. L., \& Johnson, A. M. (2008). Rapid business and IT change: drivers for strategic information systems planning, European Journal of Information Systems, volume 17, pp 198-218.

Newkirk, H. E., Lederer, A. L., \& Srinivasan, C. (2003). Strategic Information Systems Planning: too little or too much, Journal of Strategic Information Systems, Volume 12, pp 201-228.

Nilsson, A., \&Ranerup, A. (2002). Improvisational change management: New work forms with groupware. Electronic government: Design, applications and management, 299-319.

Nyella, E. \&Mndeme, M. (2010) Power Tensions in Health Information System Integration in Developing Countries: The Need for Distributed Control, Electronic Journal ofInformation Systems in Developing Countries 43, 4, 1-19.

O'Connor, G., \&Smallman, C. (1995). The hybrid manager: a review. Management Decision, 33(7), 19-28.

Osman, E., (2012). Developing strategic information systems planning model in Lybiaorganisations.Plymouth: School of Management, Plymouth University.

Pant, S., \& Hsu, C. (1995). Strategic information systems planning: a review. In Information Resources Management Association International Conference.

Reich, B. H., \&Benbasat, I. (2000).Factors that influence the social dimension of alignment between business and information technology objectives.MIS quarterly, 81-113.

Sahay, S. \& Walsham, G. (2006) Scaling of Health Information Systems in India: Challenges and Approaches.Information Technology for Development, 12, 3, 185-200.

Sahay, S., Monteiro, E. \&Aanestad, M. (2009) Toward a Political Perspective of Integration in Information Systems Research: The Case of Health Information Systems in India. Information Technology for Development, 15, 2, 83-94.

Samaha, K., \&Dahawy, K. (2010).Information System Strategy Development and Implementation in the Egyptian Small and Medium Construction Enterprises.E-strategies for Technological Diffusion and Adoption: National ICT Approaches for Socioeconomic Development, 88. 
Smits, M. T., Van der Poel, K. G., \&Ribbers, P. M. (1997).Assessment of information strategies in insurance companies in the Netherlands.The Journal of Strategic Information Systems, 6(2), 129-148.

Teo, T. S., \&Ang, J. S. (2001). An examination of major IS planning problems. International Journal of Information Management, 21(6), 457470.

Teubner. (2007). Strategic information systems planning: A case study from the financial services industry, Journal of Strategic Information Systems, Vol. 16 .105-125.

Wall, P. J., Vallieres F., Lewis, D. Hederman, L. \& Musa, J. (2013).A SocioTechnical Approach to the Implementation of mHealth in Sierra Leone: A Theoretical Perspective, eChallenges e-2013 Conference Proceedings, Paul Cunningham and Miriam Cunningham (Eds) IIMC International Information Management Corporation, ISBN: 978-1-905824-40-3

Wall, P. J., Vallieres F., Nestle, N. \&Boombu-Johnson C. (2013). Technical Implications of Implementing mHealth Applications in Sierra Leone, eChallenges e-2013 Conference Proceedings, Paul Cunningham and Miriam Cunningham (Eds) IIMC International Information Management Corporation, ISBN: 978-1-905824-40-3

Ward, J.M., Galliers, R.D., \&Thorogood, A. (2014). Information systems strategy as practice: Micro strategy and strategizing for IS. The Journal of Strategic Information Systems, 23(1), 1-10.

Watson, R.T., Kelly, G.G., Galliers, R.D., \&Brancheau, J.C. (1997). Key issues in information systems management: an international perspective. Journal of Management Information Systems, 91-115.

WHO (2012).National e-Health Strategy for Improving Women \& Children's Health, World Health Organization.

Wiggins, R.W. (1995). The Internet for Everyone: A Guide for Users and Providers, New York: McGraw-Hill.

Wilson, T. D (1989). The Implementation of Information Systems Strategies in UK Companies: Aims and Barriers to Success, International Journal of Information Management, Vol. 9. pp 245-258.

World Health Organization (2012). 'e-Health tools and Services, Global Observatory for eHealth report' WHO/EHL/06.1.

World Health Organization (2012).World health statistics 2012.World Health Organization.

Worthen, B. (2007). The IT Factor: Tech Staff's Bigger Role, Wall Street Journal, December 4, 2007. 